\title{
A Randomised, Double-Blind, Placebo-Controlled Trial of As-Needed Naltrexone in the Treatment of Pathological Gambling
}

\author{
Leena Kovanen $^{a}$ Syaron Basnet ${ }^{a, e}$ Sari Castrén ${ }^{b, c}$ Maiju Pankakoskia \\ Sirkku T. Saarikoski ${ }^{c}$ Timo Partonen ${ }^{a}$ Hannu Alho ${ }^{b, c}$ Tuuli Lahti ${ }^{b, e}$ \\ ${ }^{a}$ Mental Health Unit and b Tobacco, Gambling and Addiction Unit, National Institute for Health and Welfare, \\ Department of Health, ${ }^{C}$ Clinicum, Internal Medicine, University of Helsinki and Helsinki University Hospital, ${ }^{d}$ Ministry \\ of Social Affairs and Health, Department of Occupational Safety and Health, Helsinki and ' Faculty of Social Sciences, \\ Department of Behavioural Sciences and Philosophy, University of Turku, Turku, Finland
}

\section{Key Words}

Randomized controlled trial · Pathological gambling ·

Naltrexone · Psychosocial support · OPRM1

\begin{abstract}
Background/Aims: Effective treatment strategies are needed for the treatment of pathological gambling (PG). The efficacy of as-needed naltrexone was assessed in a single-centre, randomised, double-blind, placebo-controlled trial. Methods: The participants $(n=101)$ received either as-needed placebo or naltrexone $(50 \mathrm{mg}$ ) and psychosocial support for 20 weeks. The primary outcome measure was the severity of PG assessed by the Yale-Brown Obsessive Compulsive Scale adapted for PG (PG-YBOCS). Secondary gambling-related outcome measures included thoughts/urges and behaviour subscales of PG-YBOCS as well as the highest daily expenditure and gambling frequency. In addition, RAND-36 scales of emotional well-being and social functioning were used as outcomes. The results were analysed using the intention-to-treat principle and linear random effects modelling. Results: No significant treatment group differences were found. In an exploratory analysis, emotional well-being increased in a subgroup of participants with $A A$ genotype of opioid receptor, mu 1 (OPRM1) A118G polymorphism ( $\mathrm{p}=$ 0.02). Conclusion: Overall, the as-needed naltrexone may
\end{abstract}

not provide substantial additional benefit for PG patients receiving psychosocial support. Replication by larger scale studies is warranted to further evaluate naltrexone administration schedules for the treatment of PG and the role of OPRM1.

(c) 2015 S. Karger AG, Basel

\section{Introduction}

Pathological gambling (PG) is a persistent and recurrent maladaptive gambling behaviour [1] with a lifetime prevalence of 1\% in Finland [2]. Currently, as no US Food and Drug Administration-approved pharmacotherapy is in existence, psychosocial approaches are the first choice of treatment [3]. Psychosocial approaches may be complemented with pharmacotherapy, as combination therapies may be more effective than monotherapies [4].

Opioid antagonists naltrexone and nalmefene have shown some evidence of effectiveness in the treatment of PG [5-12]. Despite their benefits, problems with adherence to daily use of naltrexone medication have limited their usability $[5,9]$. One solution could be as-needed ad-

S.B. and L.K. contributed equally to this work.

Tuuli Lahti

Tobacco, Gambling and Addiction Unit

National Institute for Health and Welfare, Department of Health PO Box 30, FI-00271 Helsinki (Finland)

E-Mail tuuli.lahti@thl.fi 
ministration, that is, taking the pharmacotherapy before gambling or when craving to gamble. As-needed naltrexone has been shown to be effective in the treatment of alcohol dependence and problem drinking [13-15]. Moreover, in our earlier non-controlled pilot study, asneeded naltrexone combined with a brief intervention decreased participants' gambling behaviour and depressive symptoms; as well as increased the subjective quality of life $[16,17]$.

In addition to the emerging data of the effectiveness of as-needed naltrexone, there is emerging data of naltrexone's pharmacological effects being modified by $A 118 G$ (Asn40Asp, rs1799971) polymorphism of opioid receptor, mu 1 (OPRM1) gene [18]. $\mu$-Opioid receptors are the main pharmacological target for naltrexone, and metaanalysis suggests that the $G$ allele lowers relapse rates of heavy drinking in response to naltrexone treatment [19]. So far, the moderating role of OPRM1 polymorphism has not been studied in PG treatment.

Based on these promising findings, this study was designed to compare the efficacy of as-needed naltrexone to placebo together with adjunctive psychosocial support in the treatment of PG. In addition, the role of OPRM1 $A 118 G$ polymorphism in moderating the treatment response was studied. We hypothesised that as-needed naltrexone would reduce gambling symptoms.

\section{Materials and Methods}

\section{Trial Recruitment}

Screening 236 persons recruited through advertisements in widely distributed free newspapers and announcements in gambling-related websites yielded 101 eligible participants (online suppl. fig. 1; for all online suppl. material, see www.karger.com/ doi/10.1159/000435876). The main inclusion criterion at prescreening over telephone was a score of 5 or over in the South Oaks Gambling Screen-Revised (SOGS-R) [20]. The inclusion criteria were age 18 or over, ability to speak Finnish, meeting the criteria for PG by Diagnostic and Statistical Manual of Mental Disorders, Fourth Edition (DSM-IV) [1] and a score of five or over in SOGS-R. Exclusion criteria were severe depression (Finnish Depression Scale (DEPS) [21] score $\geq 25$ ), bipolar disorder (indication of mania/hypomania with Mood Disorder Questionnaire (MDQ) [22]), suicide risk (assessed by a medical doctor), self-reported medical conditions (e.g. acute hepatitis, severe liver or kidney dysfunction, substance abuse or pregnancy), simultaneous participation in other PG-related trials, lack of reliable contact information, being a prisoner, mental retardation or use of opioid antagonists or agonists. Excluded individuals were directed to online self-help websites.

This trial was conducted between May 2011 and May 2013 in a single-centre setting at the Problem Gambling Clinic of Helsinki Metropolitan area in accordance with the principles of the Declaration of Helsinki and Good Clinical Practice, and was started only after Ethics Committee approval (permission EudraCT number: 2010-021123-26; sponsor's protocol code number: 03062010; Ethics Committee number: 193/13/03/00/2010). All the participants gave written informed consent.

\section{Pharmacotherapy and Psychosocial Support}

Participants $(\mathrm{n}=101)$ were randomized in 1:1 ratio according to a computer-generated randomisation list to a double-blind, placebo-controlled 20-week treatment with as-needed, self-administered pharmacotherapy $(50 \mathrm{mg}$ naltrexone or indistinguishable placebo capsules received free of charge from AOP Orphan) with no titration period. Participants and staff were all blind to the treatment assignment. Two sets of sealed envelopes containing study medication details for each patient were to be broken only in case of an emergency.

Participants were instructed to take one capsule, up to once daily, always in an as-needed manner when planning to gamble or when experiencing a strong urge to gamble (preferably 30-60 min before gambling for proper absorption of the pharmacotherapy). Participants were provided 30 capsules every 4 weeks if needed. Medication compliance was evaluated by the pills taken based on participants' self-report marked in their gambling/medication diary. The diary was checked at each trial visit. Safety assessment at each visit included follow-up of adverse events, vital signs and mood states.

The trial altogether included eight visits (online suppl. table 1). In addition to pharmacotherapy, all participants received psychosocial support to enhance medication and treatment compliance. Psychosocial support was described within a framework of the BRENDA model [23]. Specific elements targeted for changing gambling behaviour (i.e. psycho-education, motivation for change, recognition of high-risk situations and coping skill enhancements) were offered by a psychologist on 3 visits. Both abstinence and reduction of gambling were accepted goals. Smoking and concomitant medication, except opioid antagonists or agonists, were allowed during the trial.

\section{Assessments}

SOGS-R, DSM-IV criteria for PG, DEPS, MDQ, and Alcohol Use Disorders Identification Test (AUDIT) [24] were assessed at screening. Gambling activity (expenditure, frequency and type of gambling) 3 weeks prior to trial was assessed by interview using the Timeline-Follow-Back (TLFB) method [25]. During the trial, gambling activity was assessed by review of the gambling/medication diary filled by the participants and at each visit by further interview with the participants.

In addition, participants were asked about their smoking (yes/ no), height, weight, onset age of active gambling ( $\geq 3$ times/week) and onset age of gambling problem (thought/decided to seek help or significant other asked to reduce gambling or to seek help). Body mass index (BMI), early onset gambling problem ( $\leq 25$ years of age) and lag time, that is, the transition from active gambling to problem gambling, were computed from the above questions. Hazardous alcohol consumption was computed from AUDIT (score $\geq 8$ for males and $\geq 7$ for females).

The predefined primary outcome measure was the total score of the Yale-Brown Obsessive Compulsive Scale adapted for PG (PG-YBOCS) [26], measuring the past 1-month severity of PG. Secondary outcome measures included changes in PG-YBOCS thoughts/urges and behaviour subscales as well as the RAND 36- 
Item Health Survey 1.0 [27] scales of emotional well-being and social functioning. In addition, gambling activity outcomes were computed from TLFB interview and gambling/medication diary. They included participants' highest daily expenditure in a week and gambling frequency as the percentage of days in a week in which gambling occurred.

\section{OPRM1 A118G Genotyping}

Saliva samples were collected using Oragene DNA Self-Collection Kit OG-500 (DNAgenotek) according to the manufacturer's instructions. Standard methods were used to extract DNA from the samples and sequence the OPRM1 A118G polymorphism at the Institute for Molecular Medicine Finland (FIMM), Technology Centre and University of Helsinki. The genotypes were analysed on Applied Bio-systems Variant Reporter software (version 1.0). Ten samples failed sequencing with the first primer set (forward primer: CAGCCAGGACTGGTTTCTGT and reverse primer: TGACCAGGAAGTTTCCGAAG) and were re-sequenced with a second set (forward primer: TACTCCTTGGATCGCTTTGC and reverse primer: GATGGAGTAGAGGGCCATGA). In total, 97\% of the samples were successfully sequenced for $A 118 G$ polymorphism. In addition, $6 \%$ of the samples were re-sequenced with the second set of primers to confirm that sequencing had no error. For genetic case-control association analysis, 506 previously genotyped (98 females) participants [28] free of mood, anxiety and substance use disorders according to DSM-IV were used as controls.

\section{Statistical Analyses}

Statistical analyses were based on the intention-to-treat principle. Treatment and genotype differences at the baseline were tested using $\chi^{2}$ test and Fisher's exact test for categorical variables and $t$ test for continuous variables. Linear random effects modelling, which accounts for repeated measures over time, was used to study the treatment effect [29]. The method was selected since it is effective in accommodating missing data, assuming missingness at random. The fixed effects of the model contained the main effects of the treatment group and follow-up time as a continuous variable, and their interaction. Models were controlled for the baseline value of the outcome, gender and genotype. Different genotypes were analysed separately. In genetic analysis, the dominant model of inheritance was assumed.

In addition, possible associations between sample characteristics and dropouts were examined using logistic regression. The logistic regression model controlling for age and gender was used for the case-control association analysis of OPRM1 A118G. Logarithmic transformation was performed for the highest daily expenditure and square root transformation for the gambling frequency for normality. Analyses were performed using R software (version 3.0.2) [30] and IBM SPSS Statistics software version 22.0 (IBM Corp., Armonk, N.Y., USA).

\section{Results}

\section{Subject Characteristics}

The participants' baseline demographics and clinical characteristics are reported in table 1 . The participants (68\% males) were on average 46 years (range from 20 to
73 years). Males were on average 16 years younger $(\mathrm{t}=$ $-5.8, \mathrm{p}<0.001)$. Smoking $(52 \%)$ and hazardous alcohol consumption (46\%) were common. No significant differences between the treatment groups or genotypes at baseline were observed except for education between the treatment groups $(\chi=6.2, \mathrm{p}=0.05)$ and females having $A G / G G$ genotype more often $(\chi=5.8, \mathrm{p}=0.02)$. Furthermore, the OPRM1 A118G genotype frequencies (table 2) of PG participants were similar to healthy controls (odds ratio (OR) $1.1,95 \%$ confidence interval $(\mathrm{CI}) 0.7-1.6, \mathrm{p}=$ $0.8)$.

Over $40 \%$ of the participants (56\% males vs. $6.9 \%$ females, $\left.\chi^{2}=20.1, p<0.001\right)$ had an early onset $(\leq 25$ years $)$ gambling problem. On average, the participants started active gambling at the age of 29 and developed a gambling problem at the age of 34 . For half of the participants, the transition took 2 years or even less. Slot machines (78\%) and weekly lotteries (44\%) were the most popular games gambled. Prior to the trial, the participants gambled on average 2-3 times per week and the average highest daily expenditure in a week was $380 €$.

\section{Treatment Adherence}

Of the 101 participants, 69 (68\%) completed the 20 - week treatment (i.e. did not dropout). The dropout rate (online suppl. fig. 1 for the reasons) was highest at the beginning (19\% from baseline to week $4,11 \%$ from week 5 to week 12, and 6\% from week 13 to week 20). Dropout analysis shows that completers did not differ significantly from dropouts with respect to the treatment group (OR 1.5, 95\% CI 0.64-3.5, p = 0.4). However, smoking (OR 4.5, 95\% CI 1.5-14.1, $\mathrm{p}=0.009$ ), lower BMI (OR $0.85,95 \%$ CI $0.73-0.99, \mathrm{p}=0.04$ ) and younger age (OR $0.96,95 \%$ CI $0.93-1.00, \mathrm{p}=0.05$ ) was associated with dropout.

Medication intake (yes/no) was reported in the gambling/medication diaries on average for $67 \%$ of the days. In the beginning, as-needed medication was taken about 3 times per week and in the end, about twice per week by the participants in the placebo group and once per week by the participants in the naltrexone group. Participants in the placebo group used the medication more often than participants in the naltrexone group $(33.0 \%$ of the days reported vs. $\left.30.1 \%, \chi^{2}=9.0, p=0.003\right)$. Participants in the naltrexone group reported adverse events twice as often as the ones in the placebo group ( 38 vs. $20 \%, \chi^{2}=4.2, p=$ 0.04 ; table 3$)$. The reported adverse events were relatively similar between the groups $\left(\chi^{2}=4.0, p=0.4\right)$. Two participants in the naltrexone group dropped out due to medication-related adverse events (online suppl. fig. 1). 


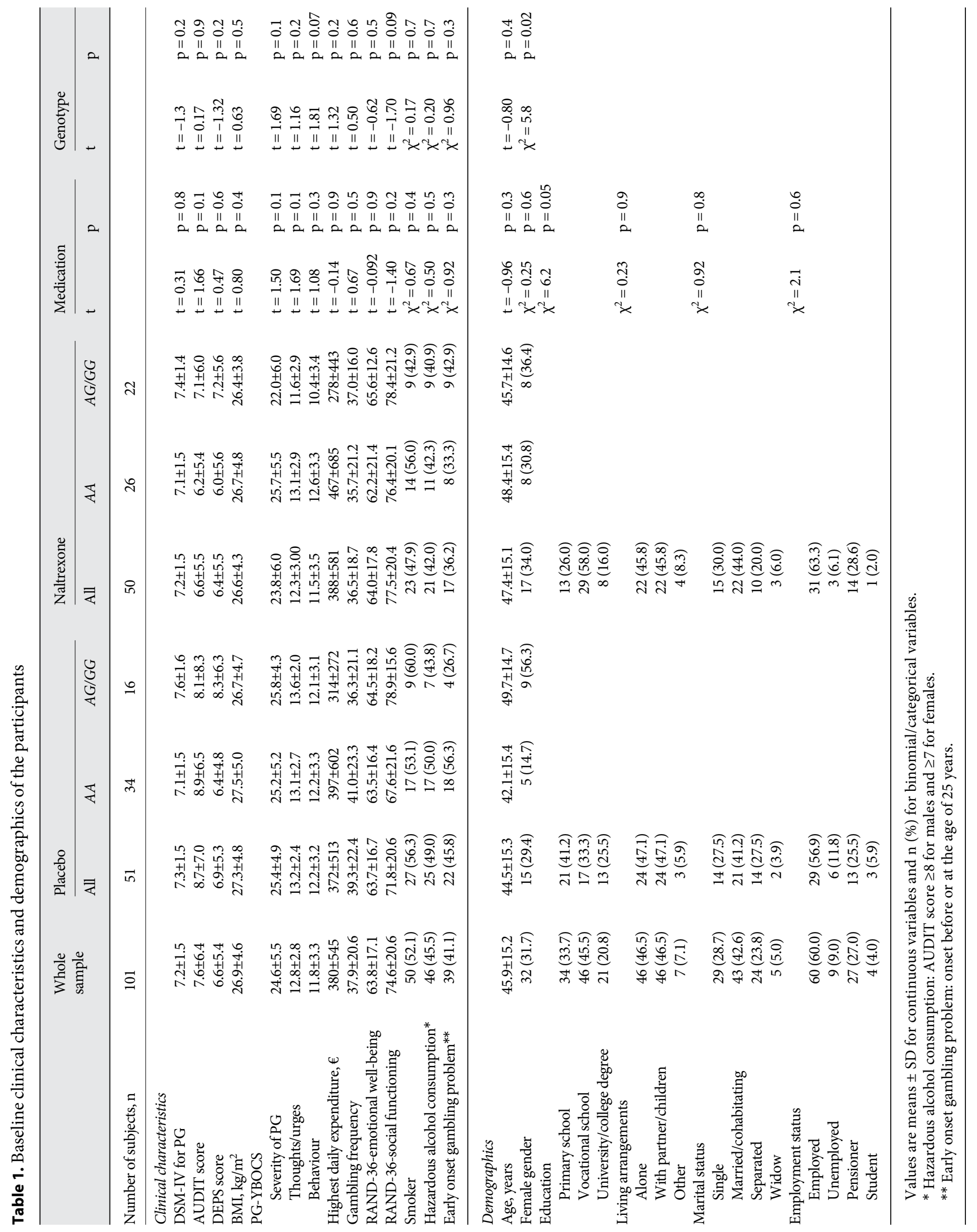


Table 2. Genotype and allele counts and frequencies and Hardy-Weinberg Equilibrium p values

\begin{tabular}{|c|c|c|c|c|c|c|}
\hline & \multicolumn{3}{|c|}{ Genotypes, n (\%) } & \multicolumn{2}{|c|}{ Alleles, n (\%) } & \multirow[t]{2}{*}{$\mathrm{p}$} \\
\hline & $A A$ & $A G$ & GG & $A$ & $G$ & \\
\hline Naltrexone & $26(54.2)$ & $20(41.7)$ & $2(4.2)$ & $72(75.0)$ & $24(25.0)$ & 0.7 \\
\hline Placebo & $34(68.0)$ & $13(26.0)$ & $3(6.0)$ & $81(81.0)$ & $19(19.0)$ & 0.3 \\
\hline Whole PG sample & $60(61.2)$ & $33(33.7)$ & $5(5.1)$ & $153(78.1)$ & 43 (21.9) & 0.8 \\
\hline Controls [28] & $320(63.2)$ & $157(31.0)$ & $29(5.7)$ & $797(78.8)$ & $215(21.2)$ & 0.1 \\
\hline
\end{tabular}

Table 3. Adverse events reported

\begin{tabular}{lll}
\hline & Naltrexone, n (\%) & Placebo, n (\%) \\
\hline Adverse events* & $19(38.0)$ & $10(19.6)$ \\
Diarrhoea/nausea & 13 & 5 \\
Headache/somatic pain & 11 & 5 \\
Restlessness/irritability & 6 & 2 \\
Insomnia & 4 & 1 \\
Others & 2 & 4 \\
No adverse events & $31(62.0)$ & $41(80.4)$ \\
\hline
\end{tabular}

* Each participant could report more than one adverse event.

However, dropouts due to medication-related adverse events did not differ significantly between the treatment groups $\left(\chi^{2}=1.8, \mathrm{p}=0.2\right)$.

\section{Treatment Response}

Severity of gambling (PG-YBOCS, $\mathrm{b}=-4.4, \mathrm{SE}=0.32$, $\mathrm{p}<0.001$ ), thoughts/urges (PG-YBOCS, $\mathrm{b}=-2.8, \mathrm{SE}=0.17$, $\mathrm{p}<0.001$ ), behaviour (PG-YBOCS, $\mathrm{b}=-2.7, \mathrm{SE}=0.16, \mathrm{p}<$ $0.001)$, gambling frequency $(\mathrm{b}=-0.3, \mathrm{SE}=0.09, \mathrm{p}=0.001)$ and highest daily expenditure $(b=-0.47, \mathrm{SE}=0.07, \mathrm{p}<$ $0.001)$ decreased and emotional well-being $(b=2.2, \mathrm{SE}=$ $0.64, p=0.001$ ) increased significantly overall with no significant difference between the treatment groups (table 4). Social functioning did not improve with time $(\mathrm{b}=0.53, \mathrm{SE}=$ $0.9, p=0.6)$ nor was there a difference between the treatment groups (table 4). In the exploratory analysis, emotional well-being increased among the subgroup of participants with $A A$ genotype $(b=3.6, \mathrm{SE}=1.5, \mathrm{p}=0.02$; table 5$)$.

\section{Discussion}

This is the first study to compare the effects of as-needed naltrexone with placebo in the treatment of PG and the possible role of OPRM1 A118G polymorphism in moder- ating the treatment response. We found no evidence in the effectiveness of as-needed naltrexone with adjunctive psychosocial support overall. In the exploratory analysis, within a subgroup of subjects with $A A$ genotype of OPRM1 A118G polymorphism, naltrexone improved participants' emotional well-being.

In the whole study population, all except one outcome improved significantly; however, no treatment group differences in response to as-needed naltrexone were observed. One explanation could be limited sample size, although the size is similar to the previous PG treatment studies [11]. Another explanation could be the lack of placebo lead-in period to exclude placebo responders. However, a study with such a period found no significant group differences when treating concurrent alcohol use disorder and PG with daily naltrexone/placebo combined with cognitive behavioural therapy [31]. On the other hand, in some previous studies, daily naltrexone has been superior to placebo in PG treatment $[5,8]$ and as-needed naltrexone combined with brief skills training has been superior to placebo in the treatment of alcohol dependency and problem drinking [13-15]. However, a recent meta-analysis does not support the observed efficacy of opioid antagonists in PG treatment due to the efficacy being significantly associated with nonadherence to the intention-to-treat principle and earlier year of publication [11]. Additionally, the aim of the psychosocial support offered may influence the effectiveness of pharmacotherapy as in alcohol dependence treatment targeted naltrexone combined with supportive therapy aimed at abstinence was not effective, whereas with cognitive behavioural therapy aimed at coping with a slip to prevent proceeding to binge drinking it was effective [13]. We accepted both abstinence and reduction of gambling as treatment goals. In our study, the psychosocial support provided to all participants or therapist effect [32-34] may have masked the effect of quite infrequently taken medication. Psychosocial support including BRENDA components [23] was chosen to include many types of 


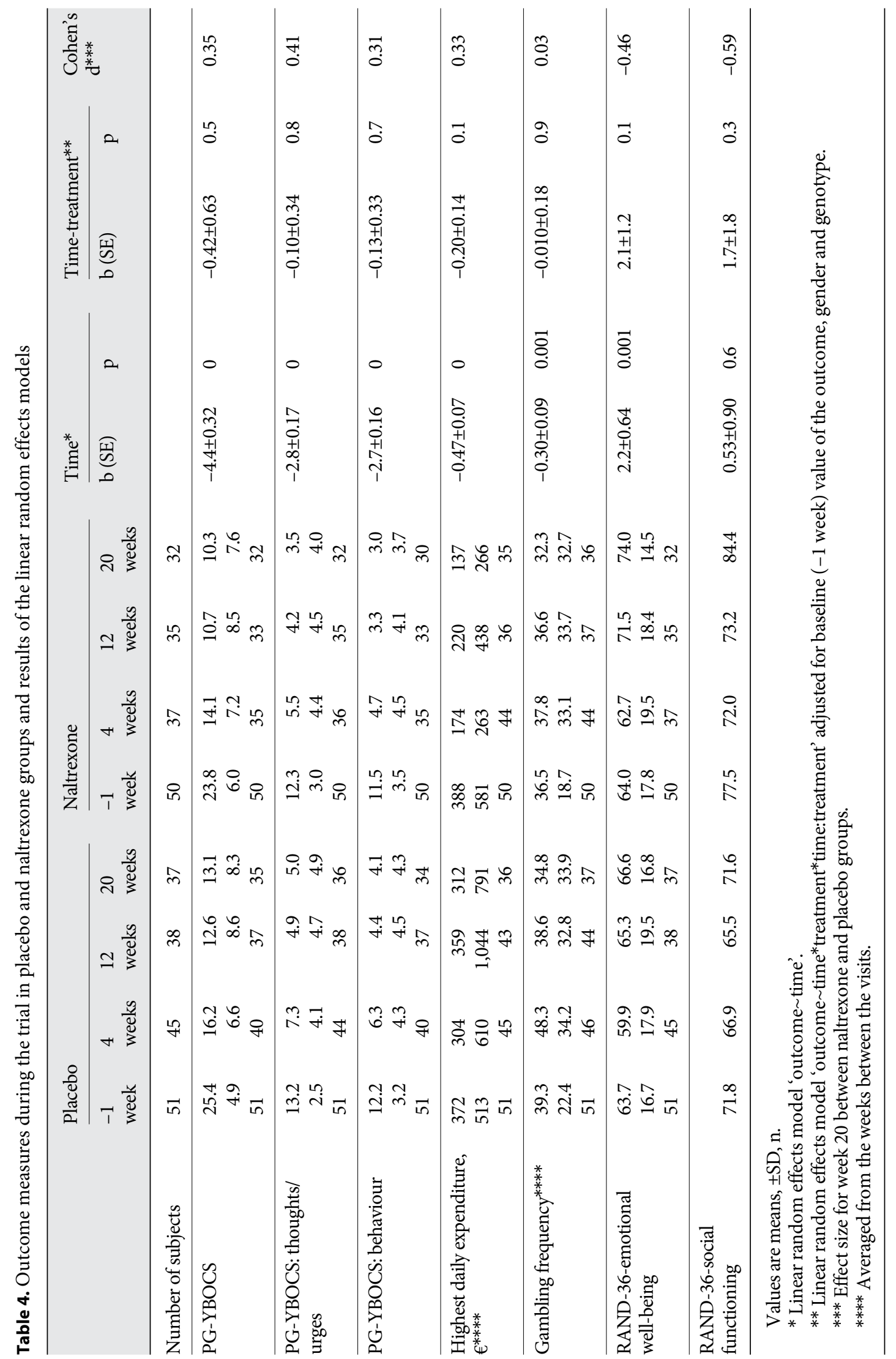




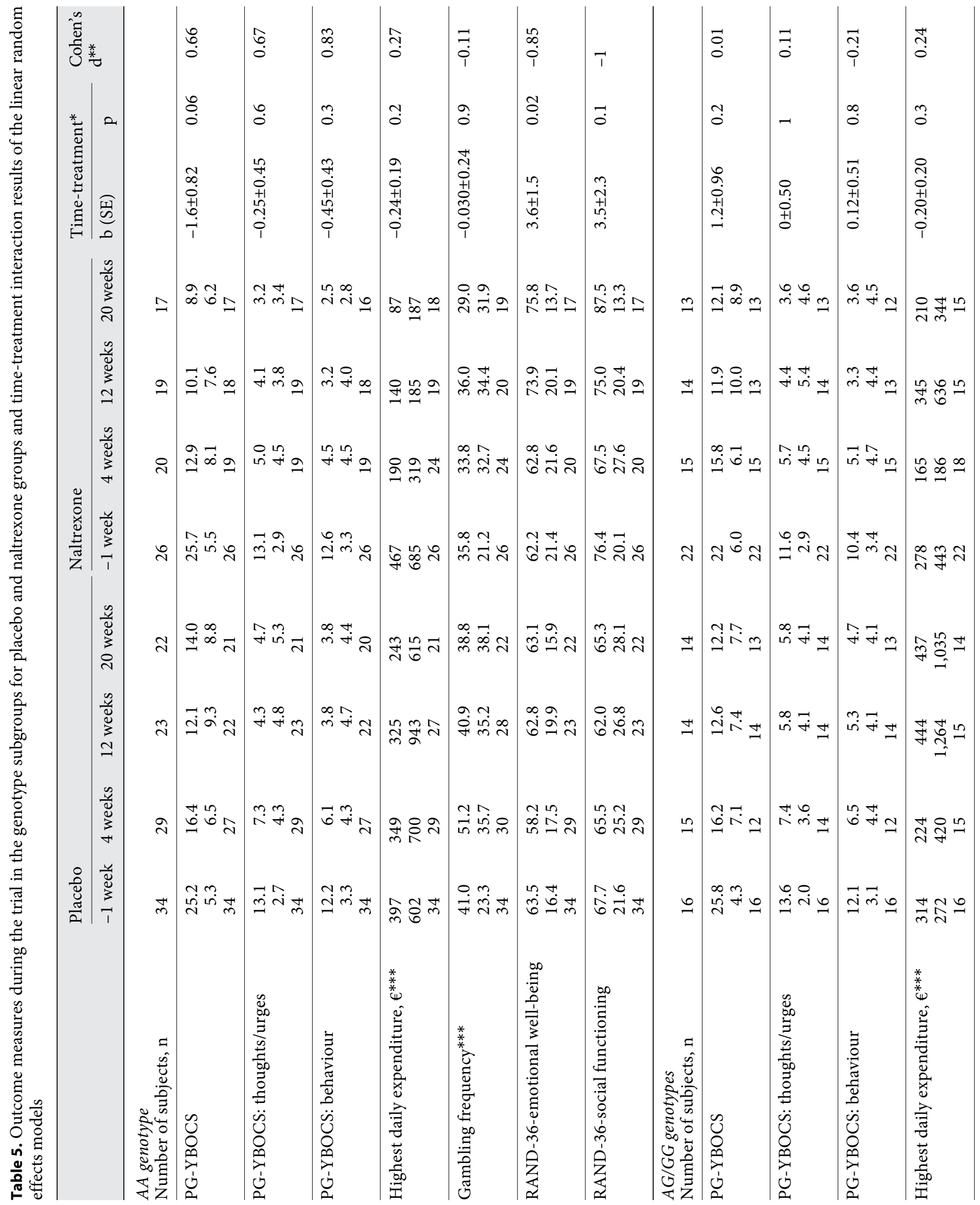




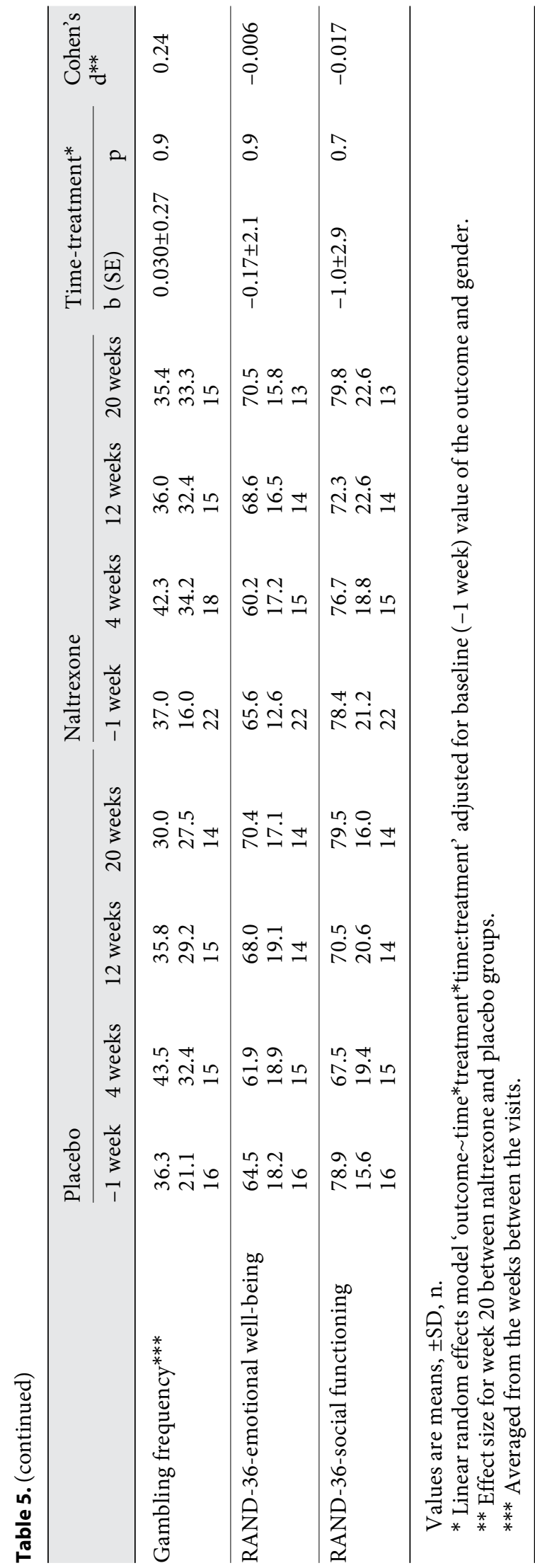

Clinical Trial of PG health care providers and to keep the intervention minimal; the elements targeted specially for gambling behaviour were offered only 3 times. Nevertheless, the psychosocial support was highly appreciated by participants based on participants' qualitative evaluation of the treatment (not reported here).

The OPRM1 A118G allele and genotype frequencies of the PG participants were similar to those reported earlier in the Finnish population [28]. Even though no evidence of OPRM1 A118G polymorphism's association with PG diagnosis compared to healthy controls was observed, it cannot be excluded that the lack of association in our data could be due to the low power of our sample to detect small effects. In the exploratory analysis of the moderating effect of OPRM1 gene on naltrexone treatment response, a significant increase in emotional well-being was observed among a subgroup of participants with the $A A$ genotype. In line with our data, $A A$ genotype has previously been linked to beneficial treatment response in the treatment of alcoholism [35]. However, several studies report that OPRM1 A118G does not modify the treatment response [36-39] or that $A G / G G$ genotype is linked to beneficial treatment response to naltrexone [40-42]. Moreover, a meta-analysis of 6 studies found that $G$ allele carriers treated with naltrexone had lower relapse rates [19]. However, the study observed no effect on abstinence rates. Our finding that naltrexone treatment provides some benefit in $A A$ homozygous individuals should be interpreted with caution due to the pharmacogenetic analysis being underpowered.

The adverse event profile of as-needed naltrexone was similar to previous data [43, 44]. Adverse events were more common in the naltrexone group with nausea being the most commonly reported adverse event. As naltrexone was taken as-needed, about $30 \%$ of the days, nausea may have continued due to participants not getting used to it and naltrexone not building up in the system. The $32 \%$ dropout rate was similar to previous PG treatment studies reporting dropout rates from 14 to $50 \%$ [45]. Smokers dropped out three times more often. This is in line with previous findings: the urge to gamble is an antecedent for relapse [46] and smokers have earlier been reported to have higher gambling urge, lower ability to control their gambling [47] and increased gambling problem severity [47-49].

This study has strengths such as fairly diverse assessments and recruitment through which our sample was community derived. Nevertheless, this study has certain limitations to be acknowledged. Due to ethical reasons, the study lacked treatment groups with no psychosocial 
support and no treatment control group. Comorbid conditions were not assessed. Attending another therapy, support group or Internet self-help program was not recorded. Sample size was limited and the participants were not randomized based on genotype. Due to dropout and exclusion criteria used, the results may not be generalizable to the larger population of pathological gamblers.

In conclusion, overall as-needed naltrexone taken quite infrequently and combined with psychosocial support was not superior to placebo. The role of OPRM1 A118G polymorphism remains inconclusive even though our exploratory analysis indicated that $A A$ genotype may moderate the treatment response to naltrexone. Replication by larger-scale studies is warranted to further evaluate naltrexone administration schedules for the treatment of PG and the role of OPRM1. In addition, further research is warranted to explore other patient characteristics possibly moderating the effect of pharmacotherapy and the effect of psychosocial support. Such characteristics could be used to match a patient to the most effective treatment.

\section{Acknowledgements}

The authors thank all participants of the trial and staff of the Helsinki Metropolitan Area Gambling Clinic for their contributions. The authors also wish to thank Clinical Research Associate Sirpa Päivinen, Senior Planning Officer Marjut Grainger, Development Manager Saini Mustalampi and Senior Scientist Päivi Laiho from the National Institute for Health and Welfare, as well as Head of Laboratory Pekka Ellonen and Scientific Laboratory Technician Oskari Torppa from the Institute for Molecular Medicine Finland and Matthew Grainger for linguistic assistance.

\section{Disclosure Statement}

The study was funded by the Ministry of Social Affairs and Health and by the National Institute for Health and Welfare (THL). The investigational product (both naltrexone and placebo) was received free of charge from AOP Orphan (AOP Orphan Pharmaceuticals AG, Wien, Austria). The Ethics Board of the Hospital District of Helsinki and Uusimaa gave permission for this trial (permission EudraCT number: 2010-021123-26; sponsor's protocol code number: 03062010; Ethics Committee number: 193/13/03/00/2010). The trial was registered under the service of the US National Institutes of Health with Clinical Trials.gov identifier: NCT01528007.

\section{References}

1 American Psychiatric Association: Diagnostic and Statistical Manual of Mental Disorders, ed 4 (DSM-IV-TR ${ }^{\circledR}$ ). Washington, American Psychiatric Press, 2000.

2 Turja T, Halme J, Mervola M, JärvinenTassopoulos J, Ronkainen JE: Suomalaisten Rahapelaaminen 2011 (Finnish Gambling 2011). Helsinki, National Institute for Health and Welfare, 2012 (cited May 6, 2014).

3 Problem Gambling Research and Treatment Centre (PGRTC): Guideline for Screening Assessment and Treatment in Problem Gambling, 2011.

4 Hosking JD, Cisler RA, Couper DJ, Gastfriend DR, Kivlahan DR, Anton RF: Design and analysis of trials of combination therapies. J Stud Alcohol Suppl 2005;15:34-42; discussion 33.

5 Kim SW, Grant JE, Adson DE, Shin YC: Double-blind naltrexone and placebo comparison study in the treatment of pathological gambling. Biol Psychiatry 2001;49:914-921.

6 Grant JE, Kim SW: Effectiveness of pharmacotherapy for pathological gambling: a chart review. Ann Clin Psychiatry 2002;14:155161.

7 Grant JE, Potenza MN, Hollander E, Cunningham-Williams R, Nurminen T, Smits G, et al: Multicenter investigation of the opioid antagonist nalmefene in the treatment of pathological gambling. Am J Psychiatry 2006; 163:303-312.
8 Grant JE, Kim SW, Hartman BK: A doubleblind, placebo-controlled study of the opiate antagonist naltrexone in the treatment of pathological gambling urges. J Clin Psychiatry 2008;69:783-789.

9 Grant JE, Odlaug BL, Potenza MN, Hollander E, Kim SW: Nalmefene in the treatment of pathological gambling: multicentre, doubleblind, placebo-controlled study. Br J Psychiatry 2010;197:330-331.

10 Anderson C, Cowlishaw S, Dowling N, Jackson A, Lorains F, Merkouris S, et al: Pharmacological interventions for the treatment of pathological and problem gambling. Cochrane Database Syst Rev 2011;1:CD008936.

11 Bartley CA, Bloch MH: Meta-analysis: pharmacological treatment of pathological gambling. Expert Rev Neurother 2013;13:887894.

12 Lupi M, Martinotti G, Acciavatti T, Pettorruso M, Brunetti M, Santacroce R, et al: Pharmacological treatments in gambling disorder: a qualitative review. Biomed Res Int 2014; 2014:537306

13 Heinälä $\mathrm{P}$, Alho $\mathrm{H}$, Kiianmaa K, Lönnqvist J, Kuoppasalmi K, Sinclair JD: Targeted use of naltrexone without prior detoxification in the treatment of alcohol dependence: a factorial double-blind, placebo-controlled trial. J Clin Psychopharmacol 2001;21:287-292.

14 Kranzler HR, Armeli S, Tennen H, Blomqvist $\mathrm{O}$, Oncken C, Petry N, et al: Targeted naltrex- one for early problem drinkers. J Clin Psychopharmacol 2003;23:294-304.

15 Kranzler HR, Tennen H, Armeli S, Chan G, Covault J, Arias A, et al: Targeted naltrexone for problem drinkers. J Clin Psychopharmacol 2009;29:350-357.

16 Lahti T, Halme JT, Pankakoski M, Sinclair D, Alho H: Treatment of pathological gambling with naltrexone pharmacotherapy and brief intervention: a pilot study. Psychopharmacol Bull 2010;43:35-44.

17 Lahti T, Halme J, Pankakoski M, Sinclair D, Alho H: Characteristics of treatment seeking Finnish pathological gamblers: baseline data from a treatment study. Int J Ment Health Addict 2013;11:307-314.

18 Garbutt JC, Greenblatt AM, West SL, Morgan LC, Kampov-Polevoy A, Jordan HS, et al: Clinical and biological moderators of response to naltrexone in alcohol dependence: a systematic review of the evidence. Addiction 2014;109:1274-1284

19 Chamorro AJ, Marcos M, Mirón-Canelo JA, Pastor I, González-Sarmiento R, Laso FJ: Association of $\mu$-opioid receptor (OPRM1) gene polymorphism with response to naltrexone in alcohol dependence: a systematic review and meta-analysis. Addict Biol 2012; 17:505-512.

20 Abbott MW, Volberg RA: The New Zealand national survey of problem and pathological gambling. J Gambl Stud 1996;12:143-160. 
21 Salokangas RK, Poutanen O, Stengård E: Screening for depression in primary care. Development and validation of the depression scale, a screening instrument for depression. Acta Psychiatr Scand 1995;92:10-16.

22 Hirschfeld RM, Williams JB, Spitzer RL, Calabrese JR, Flynn L, Keck PE Jr, et al: Development and validation of a screening instrument for bipolar spectrum disorder: the Mood Disorder Questionnaire. Am J Psychiatry 2000;157:1873-1875.

23 Starosta AN, Leeman RF, Volpicelli JR: The BRENDA model: integrating psychosocial treatment and pharmacotherapy for the treatment of alcohol use disorders. J Psychiatr Pract 2006;12:80-89.

24 Saunders JB, Aasland OG, Babor TF, de la Fuente JR, Grant M: Development of the alcohol use disorders identification test (AUDIT): WHO collaborative project on early detection of persons with harmful alcohol consumption-II. Addiction 1993;88:791-804.

25 Sobell LC, Sobell MB: Timeline follow-back: a technique for assessing self-reported alcohol consumption; in Litten RZ, Allen JP (eds): Measuring Alcohol Consumption: Psychosocial and Biochemical Methods. Totowa, Humana Press, 1992, pp 41-72.

26 Pallanti S, DeCaria CM, Grant JE, Urpe M, Hollander E: Reliability and validity of the pathological gambling adaptation of the YaleBrown Obsessive-Compulsive Scale (PGYBOCS). J Gambl Stud 2005;21:431-443.

27 Aalto AM, Aro AR, Teperi J: Rand-36 Terveyteen Liittyvän Elämänlaadun Mittarina: Mittarin Luotettavuus ja Suomalaiset Väestöarvot. Helsinki, Stakes, Tutkimuksia, 1999, vol 101, pp 1-78.

28 Rouvinen-Lagerstrom N, Lahti J, Alho $\mathrm{H}$, Kovanen L, Aalto M, Partonen T, et al: $\mu$-Opioid receptor gene (OPRM1) polymorphism A118G: lack of association in Finnish populations with alcohol dependence or alcohol consumption. Alcohol Alcohol 2013;48: 519-525.

29 Laird NM, Ware JH: Random-effects models for longitudinal data. Biometrics 1982;38: 963-974.

30 R Core Team: R: A Language and Environment for Statistical Computing. Vienna, Austria, 2013.
31 Toneatto T, Brands B, Selby P: A randomized, double-blind, placebo-controlled trial of naltrexone in the treatment of concurrent alcohol use disorder and pathological gambling. Am J Addiction 2009;18:219-225.

32 Artkoski T, Saarnio P: Therapist effects in substance abuse treatment: a naturalistic study. J Subst Use 2012;17:456-467.

33 Horvath AO, Bedi RP: Psychotherapy Relationships That Work: Therapist Contributions and Responsiveness to Patients: Therapist Contributions and Responsiveness to $\mathrm{Pa}$ tients. New York, Oxford University Press, 2002.

34 Meier PS, Barrowclough C, Donmall MC: The role of the therapeutic alliance in the treatment of substance misuse: a critical review of the literature. Addiction 2005; 100: 304-316.

35 O'Malley SS, Robin RW, Levenson AL, GreyWolf I, Chance LE, Hodgkinson CA, et al: Naltrexone alone and with sertraline for the treatment of alcohol dependence in Alaska natives and non-natives residing in rural settings: a randomized controlled trial. Alcohol Clin Exp Res 2008;32:1271-1283.

36 Rubio G, Ponce G, Jiménez-Arriero MA, Hoenicka J, Ampuero I, Ramos JA, et al: Polymorphism for m-opioid receptor $(+118)$ as a prognostic variable of naltrexone in alcohol dependence treatment: preliminary results. Eur Neuropsychopharmacol 2002; 12:397.

37 Gelernter J, Gueorguieva R, Kranzler HR, Zhang H, Cramer J, Rosenheck R, et al: Opioid receptor gene (OPRM1, OPRK1, and OPRD1) variants and response to naltrexone treatment for alcohol dependence: results from the VA cooperative study. Alcohol Clin Exp Res 2007;31:555-563.

38 Coller JK, Cahill S, Edmonds C, Farquharson $\mathrm{AL}$, Longo $\mathrm{M}$, Minniti $\mathrm{R}$, et al: OPRM1 A118G genotype fails to predict the effectiveness of naltrexone treatment for alcohol dependence. Pharmacogenet Genomics 2011; 21:902-905.

39 Arias AJ, Gelernter J, Gueorguieva R, Ralevski E, Petrakis IL: Pharmacogenetics of naltrexone and disulfiram in alcohol dependent, dually diagnosed veterans. Am J Addict 2014; 23:288-293.
40 Oslin DW, Berrettini W, Kranzler HR, Pettinati H, Gelernter J, Volpicelli JR, et al: A functional polymorphism of the mu-opioid receptor gene is associated with naltrexone response in alcohol-dependent patients. Neuropsychopharmacology 2003;28:15461552.

41 Anton RF, Oroszi G, O’Malley S, Couper D, Swift R, Pettinati H, et al: An evaluation of mu-opioid receptor (OPRM1) as a predictor of naltrexone response in the treatment of alcohol dependence: results from the combined pharmacotherapies and behavioral interventions for alcohol dependence (COMBINE) study. Arch Gen Psychiatry 2008;65:135-144.

42 Kim SG, Kim CM, Choi SW, Jae YM, Lee HG, Son BK, et al: A micro opioid receptor gene polymorphism (A118G) and naltrexone treatment response in adherent Korean alcohol-dependent patients. Psychopharmacology (Berl) 2009;201:611-618.

43 Schecter AJ, Friedman JG, Grossman DJ: Clinical use of naltrexone (EN-1639A): part I: safety and efficacy in pilot studies. Am J Drug Alcohol Abuse 1974;1:253-269.

44 Schecter A: Clinical use of naltrexone (EN 1639 A). Part II: experience with the first 50 patients in a New York city treatment clinic. Am J Drug Alcohol Abuse 1975;2:433-442.

45 Melville KM, Casey LM, Kavanagh DJ: Psychological treatment dropout among pathological gamblers. Clin Psychol Rev 2007;27: 944-958.

46 Van Holst RJ, van den Brink W, Veltman DJ, Goudriaan AE: Brain imaging studies in pathological gambling. Curr Psychiatry Rep 2010; 12:418-425.

47 Petry NM, Oncken C: Cigarette smoking is associated with increased severity of gambling problems in treatment-seeking gamblers. Addiction 2002;97:745-753.

48 Odlaug BL, Stinchfield R, Golberstein E, Grant JE: The relationship of tobacco use with gambling problem severity and gambling treatment outcome. Psychol Addict Behav 2013;27:696-704.

49 Castrén S, Basnet S, Salonen AH, Pankakoski M, Ronkainen J-E, Alho H, et al: Factors associated with disordered gambling in Finland. Subst Abuse Treat Prev Policy 2013; $8: 24$. 